\title{
Evolution of human diseases
}

\section{Harem Othman Smail}

Department of Biology, Faculty of science and health, Koya University Koya KOY45, Kurdistan Region-F. R. Iraq

\section{Abstract}

The main aims of this review were to understand the roles of evolutionary process in human disease. The suffering of human from disease may be millions years ago and until now are continuing and the human disease can be classified into many types based on their sources such as bacterial, Genetics and viral. For the past sixty years the scientist carried out high number of experiment to understand and the decision of the evolutionary process impact of the human disease. the main example of effect of evolution on the human health are using overuse of antibiotics against bacterial infection and the results to the speedy evolution of bacteria that are resistant to multiple antibiotics such that even vancomycin. The process of natural selection which is proposed by Charles Darwin play vital roles in Biological and medical process and also helps to predict and find the relationship between natural selection process of evolution and phenotypical traits. Understanding the developmental and genetic underpinnings of unique evolutionary changes have been hindered by way of insufficient databases of evolutionary anatomy and through the lack of a computational method to become aware of underlying candidate genes and regulators to the developing o the process of the evolution with helps of other branches of modern sciences such as genetics, Bioinformatics, epidemiology, ecology, microbiology, molecular biology and biochemistry.

\section{Article History}

Received 05 May 2020

Accepted 16 June 2020

Keyword

Gene conversion,

Drug-resistant,

Natural ecosystems,

Evolution,

Charles Darwin,

Genetic variation.

\section{Introduction}

For tens of millions of years, human beings and their ancestors suffered from diseases -- each the variety prompted with the aid of infectious pathogens (e.g., bacteria, viruses, parasites) and the form precipitated through our own our bodies as they age and degenerate (Armelagos et al., 1996). In two randomly selected human genomes, 99.9\% of the DNA sequence are identical (Das et al., 2009). The recent speedy accumulation of functionalgenomics and proteomics statistics provides perception into establishing the evolutionary relationship between the genotypes and phenotypes of human diseases (Park et al., 2012). The latest extent in genomics statistics is revealing a sudden point of view of gene loss as a pervasive source of genetic variation that can purpose adaptive phenotypic diversity (Albalat and Cañestro 2016). 
Gene conversion, one amongst the two mechanisms of homologous recombination, involves the unifacial transfer of genetic artifact from a 'donor's sequence to an amazingly homologous 'acceptor (Chen et al., 2007.). Genetic and mutational statistics on a growing, wide variety of issues have illustrated how phenotypic effects can end result from the mixed action of alleles in many genes (Badano and Katsanis 2002). Comparative analysis across ethnically various human populations and across human and dehumanised primate species is vital for reconstructing human organic process history and for perception the genetic foundation of the human ailment (Tishkoff and Verrelli 2003). One central motive of genome sequencing initiatives is to impact a better understanding of the genetics of disease and furnish assistance with the identification of disease-associated genes (Miller and Kumar 2001). Most genes worried in fundamental cell approaches have already developed in the unicellular ancestor of eukaryotes. Other massive agencies of genes, most exceedingly those concerned in signaling processes, can be traced back to multicellular metazoan evolution (Domazet-Lošo and two Tautz 2008).

Identifying the causes of similarities and variations in genetic ailment prevalence amongst humans is central to the perception sickness etiology. While current citizenry aren't powerfully differentiated, Brobdingnagian amounts of genomic information currently build it viable to find out regarding refined patterns of genetic variation (Prohaska et al., 2019.). Advances in genetic science and computing unit of measurement reworking the aptitude for the characterization of organic systems and researchers area unit currently poised for a precision-focused transformation within the approach they put together for and reply to, infectious diseases (Ladner et al., 2019.). Sociocultural transitions and clinical advancements will disrupt biological process equilibriums underlying trendy human anatomy, physiology and existence history (Mitteroecker 2019). Infectious diseases of domesticated animals affect human well-being through food insecurity, loss of livelihoods, and human infections (Farrell and Davies 2019).

\section{Evolution of bacterial disease}

The great social and financial have an effect on of bacterial pathogens, from drugresistant infections in hospitals to the devastation of agricultural resources, has resulted in main funding to understand the causes and penalties of pathogen evolution (Jackson et al., 2011). Pathogenic microorganism utilizes a number of mechanisms to cause sickness in human hosts. Bacterial pathogens categorical a large variety of molecules that bind host cell targets to facilitate a variety of special host responses. The molecular strategies used by using micro organism to interact with the host can be special to particular pathogens or conserved across quite a few one of a kind species (Wilson et al., 2002). Recent advances in metagenomics lookup have generated a bounty of data that gives a perception into the dynamic genetic trade happening between bacteriophage (phage) and their bacterial hosts. Metagenomic researchers of the microbiomes from a range of environments have proven that many of the genes sequenced are of phage origin. Among these genes are phageencoded exotoxin genes (Casas and Maloy 2011).

The cell-surface proteins of the infecting microorganism Streptococcus and Staphylococcus are probably involved in the process of injection. These proteins share many points which include secretion signal peptides, cell-wall spanning regions, membrane anchor domains and repeated domains of a variety of functions. These common elements can also have advanced with the aid of gene duplication and swapping of gene fragments (Goward et al., 1993). The essential microbial ailments affecting marine cultured bivalves have been 
revised on the groundwork of the etiologic agents, pathogenesis and pathogenicity. Several current bivalve-interaction models area unit studied, at the side of cellulose larvae-Vibrio pectinicida, brown brown rot, juvenile oyster unwellness, Pacific oyster nocardiosis and summer mortalities of oysters (Paillard et al., 2004). Many of the foremost virulent microorganism pathogens square measure genetically monomorphic, and perception their organic process and phylogeographic patterns can assist our understanding of the outcomes of communicable disease on human records (Achtman 2008).

\section{Relationship between evolution of bacterial disease and antibiotics}

When seen from an evolutionary perspective, manifestations of infectious diseases can be categorized as (1) variations of the host to counteract damaging components of the disease, (2) variant of the pathogen to manipulate the host, or (3) "side effects" of the sickness that do now not serve adaptive features for either the host or the pathogen. Although the features of most manifestations are not known, help or rejection of these hypotheses ought to be effectively derivable in many cases from analyses of existing records and tremendously simple experiments (Ewald 1980). Bacterial adaptation to antibiotics has been very profitable and over the past decade the expand in antibiotic resistance has generated large medical issues (Andersson two 2003).In addition to sterilisation international ecology, science and human public boom conjointly have an effect on organic process trajectories, dramatically fast organic process alternate in alternative species, above all in commercially vital, pest, and illness organisms. Such adjustments are apparent in antibiotic and human immunodeficiency virus (HIV) resistance to drugs, plant and insect resistance to pesticides, fast changes in invasive species, life-history trade in industrial fisheries, and pest adaptation to biological engineering merchandise (Palumbi 2001). Since their introduction for human remedy 60 years ago, antibiotics have shown to be a fantastic success and represent one of the most applicable scientific inventions for reducing human morbidity and mortality. Unfortunately, the intensive use and misuse of antibiotics have resulted in antibiotic resistance amongst several human pathogens, decreasing the possibilities for infections' treatment and jeopardizing clinical procedures, such as organ transplantations or implants of prostheses, where infective problems are frequent and antibiotic remedy is wished to forestall or deal with these infections. There are two important mechanisms concerned with the improvement of antibiotic resistance, particularly mutation two and acquisition of resistance genes two by way of horizontal gene switch (HGT). Given that human pathogens had been inclined to antibiotics earlier than the use of these capsules for the therapy of infections, the beginning of antibiotic resistance determinants obtained through HGT must necessarily lay in the non-pathogenic microbiosphere (Martinez 2009). The remedy of infectious disorder is compromised by using the development of antibiotic-resistant lines of microbial pathogens. A range of biochemical methods is concerned that might also maintain antibiotics out of the cell, alter the target of the drug, or disable the antibiotic. Studies have proven that resistance determinants occur by means of either of two genetic mechanisms: mutation and acquisition (Mazel 1999).

Natural ecosystems incorporate a large quantity of possible resistance genes; nevertheless, just a few of them are currently existing in gene-transfer units and disseminated among pathogens. Along the review, the tactics implied in this situation and the penalties for the future evolution of resistance and the environmental microbiota are discussed two (Baquero et al., 2009).For the past 60 years or so, we have carried out at an international experiment in evolutionary decision pressure by means of making use of tonnes of antibiotics 
to the planet, to treat patients and to promote growth in animals used for meals production. The consequences are solely too depressing apparent-widespread antibiotic resistance in pathogens. This manner is Darwinian "natural" selection, at the sharp end. Each year, thousands of people die from hospital-acquired bacterial infection, a whole lot of which is multi-drug resistant. This disaster is pushed by means of overuse of antibiotics and our incapability to manage the dissemination of bacteria and their drug-resistance genes (Salmond and Welch 2008). The therapy of bacterial infections is increasingly intricate due to the fact microorganisms can develop resistance to antimicrobial marketers (Martínez 2007). Overuse of antibiotics in humans and farm animals has led to the speedy evolution of bacteria that are resistant to multiple tablets such that even vancomycin, the drug of last resort, is no longer fantastic in opposition to some strains. Apart from the discovery and exploitation of the herbal peptide antimicrobial dealers that structure part of the innate immune system of plant life and animals, there have been few new antibiotics developed in latest (Tan et al., 2000).

Understanding the stipulations that favor the evolution and maintenance of antibiotic resistance is the central goal of epidemiology. A imperative function explaining the adaptation to harsh, or 'sink', environments is the supply of advisable mutations by way of migration from a 'source' population. Given that antibiotic resistance is frequently related to opposing pleiotropic health costs, the expanded migration fee is estimated not only to enlarge the fee of resistance evolution, but additionally to amplify the likelihood of fixation of resistance mutations with minimal fitness fees (Perron et al., 2007). Antibiotic resistance is one of the greatest challenges of the twenty-first century. However, the growing grasp of bacterial pathogenesis and intracellular verbal exchange has printed many plausible techniques to increase novel tablets to deal with bacteria-mediated disorder (Rasko and Sperandio 2010). Bacteria can gather target-mediated antibiotic resistance in three ways. The first is the accumulation of factor mutations in the chromosomal gene encoding the goal (Maiden 1998). The biofilm mode of life gives benefits to microorganisms, such as improved resistance towards environmental stresses, consisting of antibiotic challenge. The neighborhood level resistance furnished by means of biofuels is distinct from resistance mechanisms that function at a cellular level, and can't be disregarded in the development of novel strategies to fight infectious diseases. The evaluate compares the mechanisms of antibiotic resistance at mobile and community ranges in the mild of past and present antibiotic discovery efforts. Future views on novel strategies for therapy of biofilm-related infectious illnesses are discover (Penesyan et al., 20150. The most normal micro organism had been coagulasenegative staphylococci (CNS) $(35 \bullet 1 \%)$, Escherichia coli $(11 \bullet 4 \%)$, Staphylococcus aureus $(9 \bullet 9 \%)$, Enterococcus spp. $(8 \bullet 2 \%)$, and Pseudomonas aeruginosa $(7 \bullet 5 \%)$. The susceptibility of CNS to oxacillin decreased from $67-44 \%$ over six years, whilst that of Enterobacteriaceae to amoxicillin and piperacillin was once decreased via about $50 \%$. P. Aeruginosa susceptibility to ceftazidime remained remarkably stable at round $90 \%$, in spite of massive empirical use ( Durand-Gasselin et al ., 1995). Many doctors will suggest ameliorations to a way of life and increasing fiber consumption. Empirical antibiotics continue to be the mainstay of therapy for sufferers with Diverticular ailment and rifaximin seems to be the high-quality choice. In extreme or relapsing disease, surgical intervention is regularly the only remaining therapy option. Although novel remedy picks are but to end up available, the addition of treatment options primarily based on Mesalazine (mesalamine) and probiotics may additionally beautify treatment efficacy (Tursi and Papagrigoriadis 2009). Evolution of micro organism closer to resistance to antimicrobial agents, inclusive of multidrug resistance, is unavoidable because 
it represents a particular aspect of the commonplace evolution of microorganism that is unstoppable. Therefore, the sole capacity of dealing with this situation is to delay the emergence and subsequent dissemination of resistant bacteria or resistance genes (Courvalin 2016).

Yersinia pestis, the causative agent of plague, looks to have developed from a gastrointestinal pathogen, Yersinia pseudotuberculosis, in simply 1,500-20,000 years - an 'eye blink' in evolutionary time. The third pathogenic Yersinia, Yersinia enterocolitica, also causes gastroenteritis however, is distantly associated with you. Pasties' and Y. Pseudotuberculosis (Wren 2003). The shared evolutionary destiny of humans and their symbiotic microorganism has chosen for mutualistic interactions that are crucial for human health, and ecological or genetic adjustments that uncouple this shared fate can result in disease. In this way, searching to ecological and evolutionary principles may provide new techniques for restoring and keeping human health (Dethlefsen et al., 2007). The discovering that horizontal gene transfer and genome decay have key roles in the evolution of bacterial pathogens was in particularly surprising. It has also turned out to be evident that even the definitions for 'pathogen' and 'virulence factor' want to be re-evaluated (Pallen and Wren 2007).

\section{Genetics and evolution}

Over 200 years ago, Erasmus Darwin famously argued that the price of what is acknowledged these days as an evolutionary strategy would be to "unravel the principle of diseases". Charles Darwin noticed hereditary sickness as proof of inheritance of version. From the book of On The Origin of Species (1859) to the 1940s, Darwinism played an important function in biological, medical, and social sciences alike (Gluckman et al., 2011). The organic process history of a factor helps predict its operate and relationship to phenotypical traits. Although sequence conservation is frequently wont to decipher factor operate and verify medical connection, ways for helpful logical thinking from comparative expression records square measure missing (Chen et al., 2019). It appears clear that the evolution of the ancestors of chimpanzees and hominins separated 7-9 million years ago with some migration out of Africa with the aid of the before hominins; Homo sapiens slowly emerged as climate change resulted in drier, much less forested African conditions. The African populations accelerated and evolved in many extraordinary prerequisites with slow mutation and selection rates in the human genome, but with an awful lot extra fast mutation going on in mitochondrial DNA (James et al., 2019). Historical elements of this evolution will be discussed. Evidence from a variety of sources shows that the human lifespan is increasing, and may nicely continue to extend to tiers that are hard to predict (Kyriazis 2019). the coding regions of the duplicates were consequently diverged from every different through nucleotide substitutions, earlier than being similarly expanded via duplications of short repeats (Djian 1998). However, the effect of the secretion on evolutionary quotes is countered through tissue-specific constraints that have been held steady over the past 75 million years (Winter et al., 2004).

Understanding the developmental and genetic underpinnings of unique evolutionary modifications has been hindered by way of insufficient databases of evolutionary anatomy and through the lack of a computational method to become aware of underlying candidate genes and regulators (Mabee et al., 2007).The suitability of the Fugu genome to facilitate the identification of candidate human sickness genes the usage of comparative positional cloning is dependent upon the extent to which synteny and gene order are conserved between the 
two species (Gilley and Fried 1999 ). Epidemiological observations have led to the hypothesis that the danger of creating some persistent noncommunicable ailments in maturity is influenced no longer only by way of genetic and person lifestyle elements however also with the aid of environmental elements appearing in early life. Research in evolutionary biology, developmental biology, and animal and human physiology affords assist for this notion (Gluckman and Hanson 2004 ). Single ester polymorphism (SNP) technologies are often accustomed recognize disease-causing genes in humans and to apprehend the interindividual variation in drug response. These areas of lookup have predominant scientific advantages (Shastry 2007).

For most of human history, the environmental demands of survival necessitated prodigious amounts of physical exertion. The avoidance of predators, hunting, gathering, and the literal "chopping wood and carrying water" of day by day existence supplied a healthful dose of bodily endeavor that obviated the need for deliberate exercise. Nevertheless, 21st century people are now immersed within an surroundings explicitly designed to do away with bodily labor (Archer and Blair 2011). In most cases, the growing organism responds to an environmental cue with the aid of producing a selectively and at once fantastic phenotype. One subset of phenotypic responses to environmental stimuli, however, does no longer necessarily provide an instant selective advantage. Rather, these sorts of responses, which we call 'predictive adaptive responses' (PARs), act primarily to improve health at a later stage of development (Gluckman et al., 2005).

Humans have evolved an awful lot longer lifespan than the wonderful apes, which rarely exceed 50 years. Since 1800, lifespans have doubled again, mostly due to upgrades in environment, food, and medicinal drug that minimized mortality at previous ages. Infections reason most mortality in wild chimpanzees and in standard forager-farmers with confined get admission to two cutting-edge medicine (Finch 2010). The controller is crucial for the suitable segregation and inheritance of genetic information. Neocentromeres are ectopic controllers that originate every so often from noncentromeric areas of chromosomes. Despite the entire absence of everyday centromeric $\alpha$-satellite DNA, human neocentromeres are capable to form a major constriction and gather a functional kinetochore. Since the invention and characterization of the primary case of somebody's neocentromere in our laboratory a decade past, 60 examples of constitutional human neocentromeres dispensed extensively throughout the genome have been described (Amor and Choo 2002).

The Sec7 area ADP-ribosylation issue (Arf) guanine nucleotide alternate elements (GEFs) are determined in all eukaryotes, and are concerned with membrane redesigning tactics for the duration of the cell (Bui et al., 2002). Multiple gene duplication and deletion events were identified in $A B C$ genes in special lineages indicating that the method of gene evolution is nevertheless ongoing. Gene duplication resulting in both gene delivery or gene death plays an important position in the evolution of the vertebrate $A B C$ genes (Moitra and Dean 2011). The forked field (Fox) household of transcription factors, which originated in unicellular eukaryotes, has extended over time through more than one duplication events, and occasionally through gene loss, to over forty individuals in mammals. Fox genes have advanced to accumulate a specialized characteristic in many key organic processes. Mutations in Fox genes have a profound result on human sickness, causing phenotypes as diverse as cancer, glaucoma and language issues (Hannenhalli and Kaestner2009). Recent work in the mouse suggests that the tail bud regulatory network relies on the interconnected activities of the Lin28/let-7 axis and the Hox13 genes. As this community is probably to be conserved in other mammals, it is feasible that the last length and the anatomical 
composition of the adult tail end result from the balance between the progenitor-promoting and -repressing things to do furnished through those genes (Mallo 2019). The diverse liquid proteins, sanctioning the survival of distinctive polar fishes in physical change seas supply uncomparable vistas into the breadth of genetic sources and mechanisms that turn out important new functions. Although most new genes evolved from preexisting genes ancestors, some are deemed to have arisen from noncoding DNA. However, the pertinent mechanisms, functions, and selective forces stay unsure (Zhuang two et al 2019). Reduced evolutionary conservation of tissue-specific genes might also characterize a bottleneck for drug projects, prompting improvement of novel fashions with a smaller evolutionary gap to humans (Ryaboshapkina and Hammar 2019).

\section{Relationship between viral disease in human and evolutionary}

A key priority for infectious disorder search is to create clear however infective agent genetic variation, modulated via host immunity, transmission bottlenecks, and epidemic dynamics, determines the big style of infective agent phylogenies observed at scales that vary from person host to populace (Grenfell et al., 2004). The recent appearance of extreme acute respiratory syndrome coronavirus (SARS-CoV) highlights the persistent risk to human health posed by way of rising viruses. However, the central procedures in the evolution of emerging viruses are unclear, specifically the selection pressures confronted by viruses in new host species (Holmes and Rambaut two 2004). While most trees confirmed evolutionary relationships steady with present day antigenic complexes and species, several adjustments to the modern classification are proposed (Powers et al., 2001). In latest years, population and evolutionary biologists have puzzled the ordinary view that parasite-mediated morbidity and mortality ¿virulence $\dot{c}$ is a primitive personality and an artifact of latest associations between parasites and their hosts. A range of hypotheses has been proposed that favor virulence and advocate that it will be maintained by way of herbal decision (Levin 1996).

Understanding the evolutionary basis for virus emergence is consequently a key research goal and many of the debates in this region can be considered within the rigorous theoretical framework set up through evolutionary genetics. In particular, the respective roles played by using natural decision and genetic flow in shaping genetic variation are also of quintessential importance of perception the nature of viral emergence (Holmes and Drummond two 2007 ). In particular, current studies have published a greater complex relationship between antigenic evolution, natural decision and resentment than earlier realized (Nelson and Holmes 2007). Evolutionary medication is defined as the utility of concepts of evolutionary theory to medical exercise and research. Among its proponents are organic anthropologists who provide a quantity of views on human evolutionary approaches and present day health challenges. Examples consist of improving the grasp of sickness resistance afforded via overuse of antibiotics and distinguishing the variations between "defenses" (healthful bodily reactions) and "defects" (unhealthful reactions) (Trevathan 2018). Recent studies have known new ways in which within which infective agent and microorganism exposures in early lifestyles engage with host genetic background/variants to change the threat for growing respiratory illness and allergic diseases. Recent research suggests that HRV-C is the important pathogenic agent related to infant wheeze, hospitalizations and likely the subsequent development of bronchial asthma (Daley 2014).

The evolutionary records of Ebola virus stays unclear. In this study, 27 Ebola virus traces with complete glycoprotein genes, which include 5 species (Zaire, Sudan, Reston, Tai Forest, Bundibugyo), have been analyzed. Here, we propose a speculation of the evolutionary 
records of Ebola virus which will be useful to look into the molecular evolution of these viruses (Li and Chen 2014). Published EBOV Makona genomes from medical samples obtained early in the outbreak in Guinea (three patients) and Sierra Leone (78 patients) (Baize et al., 2014, Gire et al., 2014) established that near-real-time sequencing could provide treasured information to researchers concerned with the international outbreak response (Park et al., 2015). Ebola outbreak in the world has ever witnessed, with over 28,000 instances and over 11,000 deaths (de La two et al., 2015). Early theories of virulence cautioned that pathogens would evolve to avirulent commensals given that harming the host would be a negative longterm survival strategy (Bull and Lauring 2014). Zika virus (ZIKV), located in 1947, had precipitated sporadic ailment at some point of Africa and Asia till the 2007 Micronesia and 2013 French Polynesia outbreaks. The rapid expansion of geographic variation and make bigger in severe pathogenicity first cited in the 2015-2016 Brazilian outbreak has raised questions involving the molecular evolution of this virus (Wang et al., 2016).

\section{Evolution of HIV viruses}

The fundamental purpose of receiving immune deficiency syndrome (AIDS) is human immunodeficiency virus type 1 (HIV-1). We have been the use of evolutionary comparisons to hint (i) the origin(s) of HIV-1 and (ii) the origin(s) of AIDS. The closest loved ones of HIV-1 are simian immunodeficiency viruses (SIVs) infecting wild-living chimpanzees (Pan troglodytes troglodytes) and gorillas (Gorilla gorilla gorilla) in west central Africa (Sharp, and Hahn 2010). Nine countries in southern Africa account for much less than $2 \%$ of the world's population, but now they characterize about one third of international HIV infections. Where normally enforced, HIV screening of donated blood and antiretroviral treatment (ART) of pregnant women have been notably superb in preventing transfusion-associated and perinatally acquired HIV, respectively (De Cock et al., 2012). Although several researchers have characterized the intrapatient evolution of viral sequences all through HIV-1 infection, potential studies inspecting intrapatient evolution throughout HIV-2 infection have been restrained (MacNeil et al., 2007). HIV-1 is swiftly evolving with growing range of international strains. In individuals, HIV-1 infection is usually initiated by one or a few transmitted/founder (TF) viruses, and within each infected person, evolves to terrific range shaped through antibody and $\mathrm{T}$ cell responses. Moreover, virus integration happens early on in infection, earlier than a protective antibody or T cells response can take place (Bonsignori et al., 2017).

Early prediction of HIV-1 composition evolution could in addition be useful for clinical observation and treatment of well contamination (Groenink et al., 1993). Molecular phylogenetics has revolutionized the determine concerning by not solely evolution however conjointly disparate fields like genetics, Bioinformatics, epidemiology, ecology, microbiology, molecular biology and biochemistry (Castro-Nallar et al., 2012). The unique milieu of the CNS fosters viral compartmentalization as well as the evolution of viral sequences, permitting for new cell types, such as macrophages and microglia, to be contaminated (Bednar et al., 2015). Often, pathogens have to adapt to correctly infect a novel host, for instance by evolving to use specific mobile surface receptors, to break out the immune response, or to ensure they are transmitted by means of the new host. In viruses there are regularly limited molecular options to attain this, and the equal sequence modifications are regularly considered every time a virus infects a particular host two (Longdon et al., 2014).

Recent tendencies contain prediction of reproducible patterns in parallel evolution experiments, forecasting the future of characterizing populations the usage of records from their past, and controlled manipulation of evolutionary dynamics (Lässig et al., 2017). Killing 
of HIV-infected cells through CD8+ T-cells imposes strong choice stress on the virus to escape (Kløverpris et al., 2016). HIV testing is the indispensable entry point for each remedy and prevention. The need to pick out acute HIV contamination (the length without delay after HIV acquisition, when folks are most infectious) and HIV-2 infection, which does no longer reply to many first-line antiretroviral agents, poses challenges for the standard algorithm of Western blot confirmation after an over and over reactive antibody screening take a look at (Branson 2010). Analysis of enormous sequence and neutralization data units showed the 332 glycan to be significantly under-represented in transmission subtype $C$ viruses compared to continual viruses, with the absence of this glycan corresponding with resistance to PGT128 (Moore et al., 2012). Viral sequence evolution also printed speedy and extraordinarily reproducible escape from these responses, mirroring the diversifications to host immune pressures found all through natural HIV-1 contamination (Dudek et al., 2012).

The virus' within-host evolutionary rates have been argued to be a lot higher than its between-host evolutionary rates. However, this conclusion depends on analyses of a quick component of the virus envelope gene (Alizon and Fraser 2013). The tree structure is presently the generic paradigm to characterize evolutionary relationships between organisms, species or different taxa. However, horizontal, or reticulate, genomic exchanges are pervasive in nature and confound characterization of phylogenetic trees. Drawing from algebraic topology, our existing a special evolutionary framework that comprehensively captures both clonal and reticulate evolution (Chan et al., 2013). Because viruses will evolve quicker than their hosts, the innate immune system of modern vertebrates is for the most phase optimized to defend towards historical viruses, alternatively than more recent viral threats. Thus, the evolutionary records of restriction factors might, in part, provide an explanation for why human beings are susceptible or resistant to the viruses existing in the modern-day world (Duggal et al., 2012). HIV evolution differs inside and among hosts and on the role played by using superb decision (Rambaut et al., 2004). Large-scale empirical analyses of the biological process dynamics of important microorganisms ar currently possible as a result of the growing convenience of pathogen sequence records and therefore the development of latest process and statistical methods of analysis (Pybus and Rambaut 2009 ). The rapidity of sequence change in RNA viruses capacity that they are useful experimental models for the learn about of evolution in ordinary and it enables us to watch them trade in 'real time', and retrace the unfold through populations with molecular phylogenies (Moya et al., 2004).

Early prediction of HIV-1 composition evolution could in addition be useful for clinical observation and treatment of well contamination (Groenink et al., 1993). Molecular phylogenetics has revolutionized the verify relating to by not solely evolution however along disparate fields like bioscience, Bioinformatics, epidemiology, ecology, microbiology, molecular biology and biochemistry (Castro-Nallar et al., 2012). The unique milieu of the CNS fosters viral compartmentalization as well as the evolution of viral sequences, permitting for new mobile phone types, such as macrophages and microglia, to be contaminated (Bednar et al., 2015). Often, pathogens have to adapt to correctly infect a novel host, for instance by evolving to use specific mobile surface receptors, to break out the immune response, or to ensure they are transmitted by means of the new host. In viruses there are regularly limited molecular options to attain this, and the equal sequence modifications are regularly considered every time a virus infects a particular host two (Longdon et al., 2014).

Recent tendencies contains prediction of duplicable patterns in parallel evolution experiments, forecasting the future of characterizing populations the usage of records from 
their past, and controlled manipulation of evolutionary dynamics (Lässig et al., 2017). Killing of HIV-infected cells through CD8+ T-cells imposes strong choice stress on the virus to escape (Kløverpris et al., 2016). HIV testing is the indispensable entry point for each remedy and prevention. The need to pick out acute HIV contamination (the length without delay after HIV acquisition, when folks are most infectious) and HIV-2 infection, which does no longer reply to many first-line antiretroviral agents, poses challenges for the standard algorithm of Western blot confirmation after an over and over reactive antibody screening take a look at (Branson 2010). Analysis of big sequence and neutralization data units showed the 332 glycan to be significantly under-represented in transmission subtype $C$ viruses compared to continual viruses, with the absence of this glycan corresponding with resistance to PGT128 (Moore et al., 2012). Viral sequence evolution also printed speedy and extraordinarily reproducible escape from these responses, mirroring the diversifications to host immune pressures found all through natural HIV-1 contamination (Dudek et al., 2012).

The virus' within-host evolutionary rates have been argued to be a lot higher than its between-host evolutionary rates. However, this conclusion depends on analyses of a quick component of the virus envelope gene (Alizon and Fraser 2013). The tree structure is presently the generic paradigm to characterize evolutionary relationships between organisms, species or different taxa. However, horizontal, or reticulate, genomic exchanges square measure pervasive in nature and confound characterization of organic process trees. Drawing from algebraic topology, our existing a special evolutionary framework that comprehensively captures both clonal and reticulate evolution (Chan et al., 2013). Because viruses will evolve quicker than their hosts, the innate immune system of modern vertebrates is for the most phase optimized to defend towards historical viruses, alternatively than more recent viral threats. Thus, the evolutionary records of restriction factors might, in part, provide an explanation for why human beings are susceptible or resistant to the viruses existing in the modern-day world (Duggal et al., 2012). HIV evolution differs inside and among hosts and on the role played by using superb decision (Rambaut et al., 2004). Large-scale empirical analyses of the biological process dynamics of important microorganisms are currently possible as a result of the growing convenience of pathogen sequence records and therefore the development of latest process and statistical methods of analysis (Pybus and Rambaut 2009 ). The rapidity of sequence change in RNA viruses capacity that they are useful experimental models for the learn about of evolution in ordinary and it enables us to watch them trade in 'real time', and retrace the unfold through populations with molecular phylogenies (Moya et al., 2004).

\section{Conclusions}

From this review I reached the following conclusions: there are no doubt the evolutionary process is raised millions years ago and has potential and impact of the developing disease for example bacterial, viral and genetics disease.

\section{References}

Achtman, M., 2008. Evolution, population structure, and phylogeography of geneically monomorphic bacterial pathogens. Annu. Rev. Microbiol., 62, pp.53-70.

Albalat, R. and Cañestro, C., 2016. Evolution by gene loss. Nature Reviews Genetics, 17(7), p.379. 
Alizon, S. and Fraser, C., 2013. Within-host and between-host evolutionary rates across the HIV-1 genome. Retrovirology, 10(1), p.49.

Amor, D.J. and Choo, K.A., 2002. Neocentromeres: role in human disease, evolution, and centromere study. The American Journal of Human Genetics, 71(4), pp.695-714.

Andersson, D.I., 2003. Persistence of antibiotic resistant bacteria. Current opinion in microbiology, 6(5), pp.452-456.

Archer, E. and Blair, S.N., 2011. Physical activity and the prevention of cardiovascular disease: from evolution to epidemiology. Progress in cardiovascular diseases, 53(6), pp.387396.

Armelagos, G.J., Barnes, K.C. and Lin, J., 1996. Disease in human evolution: the reemergence of infectious disease in the third epidemiological transition.

Badano, J.L. and Katsanis, N., 2002. Human genetics and disease: Beyond Mendel: an evolving view of human genetic disease transmission. Nature Reviews Genetics, 3(10), p.779.

Baquero, F., Alvarez-Ortega, C. and Martinez, J.L., 2009. Ecology and evolution of antibiotic resistance. Environmental Microbiology Reports, 1(6), pp.469-476.

Bednar, M.M., Sturdevant, C.B., Tompkins, L.A., Arrildt, K.T., Dukhovlinova, E., Kincer, L.P. and Swanstrom, R., 2015. Compartmentalization, viral evolution, and viral latency of HIV in the CNS. Current HIV/AIDS Reports, 12(2), pp.262-271.

Bonsignori, M., Liao, H.X., Gao, F., Williams, W.B., Alam, S.M., Montefiori, D.C. and Haynes, B.F., 2017. Antibody-virus co-evolution in HIV infection: paths for HIV vaccine development. Immunological reviews, 275(1), pp.145-160.

Branson, B.M., 2010. The future of HIV testing. JAIDS Journal of Acquired Immune Deficiency Syndromes, 55, pp.S102-S105.

Bui, Q.T., Golinelli-Cohen, M.P. and Jackson, C.L., 2009. Large Arf1 guanine nucleotide exchange factors: evolution, domain structure, and roles in membrane trafficking and human disease. Molecular Genetics and Genomics, 282(4), pp.329-350.

Bull, J.J. and Lauring, A.S., 2014. Theory and empiricism in virulence evolution. PLoS pathogens, 10(10), p.e1004387.

Casas, V. and Maloy, S., 2011. Role of bacteriophage-encoded exotoxins in the evolution of bacterial pathogens. Future microbiology, 6(12), pp.1461-1473.

Castro-Nallar, E., Pérez-Losada, M., Burton, G.F. and Crandall, K.A., 2012. The evolution of HIV: inferences using phylogenetics. Molecular phylogenetics and evolution, 62(2), pp.777-792.

Chan, J.M., Carlsson, G. and Rabadan, R., 2013. Topology of viral evolution. Proceedings of the National Academy of Sciences, 110(46), pp.18566-18571.

Chen, J., Swofford, R., Johnson, J., Cummings, B.B., Rogel, N., Lindblad-Toh, K., Haerty, W., Di Palma, F. and Regev, A., 2019. A quantitative framework for characterizing the evolutionary history of mammalian gene expression. Genome research, 29(1), pp.5363.

Chen, J.M., Cooper, D.N., Chuzhanova, N., Férec, C. and Patrinos, G.P., 2007. Gene conversion: mechanisms, evolution and human disease. Nature Reviews Genetics, 8(10), p.762. 
Courvalin, P., 2016. Why is antibiotic resistance a deadly emerging disease?. Clinical Microbiology and Infection, 22(5), pp.405-407.

Daley, D., 2014. The evolution of the hygiene hypothesis: the role of early-life exposures to viruses and microbes and their relationship to asthma and allergic diseases. Current opinion in allergy and clinical immunology, 14(5), pp.390-396.

Das, R., Hampton, D.D. and Jirtle, R.L., 2009. Imprinting evolution and human health. Mammalian Genome, 20(9-10), pp.563-572.

De Cock, K.M., Jaffe, H.W. and Curran, J.W., 2012. The evolving epidemiology of HIV/AIDS. Aids, 26(10), pp.1205-1213.

de La Vega, M.A., Stein, D. and Kobinger, G.P., 2015. Ebolavirus evolution: past and present. PLoS pathogens, 11(11), p.e1005221.

Dethlefsen, L., McFall-Ngai, M. and Relman, D.A., 2007. An ecological and evolutionary perspective on human-microbe mutualism and disease. Nature, 449(7164), p.811.

Djian, P., 1998. Evolution of simple repeats in DNA and their relation to human disease. Cell, 94(2), pp.155-160.

Domazet-Lošo, T. and Tautz, D., 2008. An ancient evolutionary origin of genes associated with human genetic diseases. Molecular biology and evolution, 25(12), pp.2699-2707.

Dudek, T.E., No, D.C., Seung, E., Vrbanac, V.D., Fadda, L., Bhoumik, P., Boutwell, C.L., Power, K.A., Gladden, A.D., Battis, L. and Mellors, E.F., 2012. Rapid evolution of HIV-1 to functional $\mathrm{CD} 8+\mathrm{T}$ cell responses in humanized BLT mice. Science translational medicine, 4(143), pp.143ra98-143ra98.

Duggal, N.K. and Emerman, M., 2012. Evolutionary conflicts between viruses and restriction factors shape immunity. Nature reviews Immunology, 12(10), p.687.

Durand-Gasselin, B., Leclercq, R., Girard-Pipau, F., Deharvengt, M.C., Rochant, H., Astier, A., Duval, J. and Cordonnier, C., 1995. Evolution of bacterial susceptibility to antibiotics during a six-year period in a haematology unit. Journal of Hospital Infection, 29(1), pp.19-33.

Ewald, P.W., 1980. Evolutionary biology and the treatment of signs and symptoms of infectious disease. Journal of theoretical Biology, 86(1), pp.169-176.

Farrell, M.J. and Davies, T.J., 2019. Disease mortality in domesticated animals is predicted by host evolutionary relationships. Proceedings of the National Academy of Sciences, 116(16), pp.7911-7915.

Finch, C.E., 2010. Evolution of the human lifespan and diseases of aging: roles of infection, inflammation, and nutrition. Proceedings of the National Academy of Sciences, 107(suppl 1), pp.1718-1724.

Gatherer, D., 2014. The 2014 Ebola virus disease outbreak in West Africa. Journal of general virology, 95(8), pp.1619-1624.

Gilley, J. and Fried, M., 1999. Extensive gene order differences within regions of conserved synteny between the Fugu and human genomes: implications for chromosomal evolution and the cloning of disease genes. Human molecular genetics, 8(7), pp.13131320. 
Gire, S.K., Goba, A., Andersen, K.G., Sealfon, R.S., Park, D.J., Kanneh, L., Jalloh, S., Momoh, M., Fullah, M., Dudas, G. and Wohl, S., 2014. Genomic surveillance elucidates Ebola virus origin and transmission during the 2014 outbreak. science, 345(6202), pp.1369-1372.

Gluckman, P.D. and Hanson, M.A., 2004. Living with the past: evolution, development, and patterns of disease. Science, 305(5691), pp.1733-1736.

Gluckman, P.D., Hanson, M.A. and Spencer, H.G., 2005. Predictive adaptive responses and human evolution. Trends in ecology \& evolution, 20(10), pp.527-533.

Gluckman, P.D., Low, F.M., Buklijas, T., Hanson, M.A. and Beedle, A.S., 2011. How evolutionary principles improve the understanding of human health and disease. Evolutionary Applications, 4(2), pp.249-263.

Goward, C.R., Scawen, M.D., Murphy, J.P. and Atkinson, T., 1993. Molecular evolution of bacterial cell-surface proteins. Trends in biochemical sciences, 18(4), pp.136-140.

Grenfell, B.T., Pybus, O.G., Gog, J.R., Wood, J.L., Daly, J.M., Mumford, J.A. and Holmes, E.C., 2004. Unifying the epidemiological and evolutionary dynamics of pathogens. science, 303(5656), pp.327-332.

Groenink, M., Fouchier, R.A., Broersen, S., Baker, C.H., Koot, M., van't Wout, A.B., Huisman, H.G., Miedema, F., Tersmette, M. and Schuitemaker, H., 1993. Relation of phenotype evolution of HIV-1 to envelope V2 configuration. Science, 260(5113), pp.1513-1516.

Hannenhalli, S. and Kaestner, K.H., 2009. The evolution of Fox genes and their role in development and disease. Nature Reviews Genetics, 10(4), p.233.

Holmes, E.C. and Drummond, A.J., 2007. The evolutionary genetics of viral emergence. In Wildlife and emerging zoonotic diseases: The biology, circumstances and consequences of cross-species transmission (pp. 51-66). Springer, Berlin, Heidelberg.

Holmes, E.C. and Rambaut, A., 2004. Viral evolution and the emergence of SARS coronavirus. Philosophical Transactions of the Royal Society of London. Series B: Biological Sciences, 359(1447), pp.1059-1065.

Jackson, R.W., Johnson, L.J., Clarke, S.R. and Arnold, D.L., 2011. Bacterial pathogen evolution: breaking news. Trends in genetics, 27(1), pp.32-40.

James, W.P.T., Johnson, R.J., Speakman, J.R., Wallace, D.C., Frühbeck, G., Iversen, P.O. and Stover, P.J., 2019. Nutrition and its role in human evolution. Journal of internal medicine, 285(5), pp.533-549.

Kløverpris, H.N., Leslie, A. and Goulder, P., 2016. Role of HLA adaptation in HIV evolution. Frontiers in immunology, 6, p.665.

Kyriazis, M., 2019. Ageing Throughout History: The Evolution of Human Lifespan. Journal of molecular evolution, pp.1-9.

Ladner, J.T., Grubaugh, N.D., Pybus, O.G. and Andersen, K.G., 2019. Precision epidemiology for infectious disease control. Nature medicine, 25(2), p.206.

Lässig, M., Mustonen, V. and Walczak, A.M., 2017. Predicting evolution. Nature ecology \& evolution, 1(3), p.0077.

Levin, B.R., 1996. The evolution and maintenance of virulence in microparasites. Emerging infectious diseases, 2(2), p.93. 
Li, Y.H. and Chen, S.P., 2014. Evolutionary history of Ebola virus. Epidemiology \& Infection, 142(6), pp.1138-1145.

Longdon, B., Brockhurst, M.A., Russell, C.A., Welch, J.J. and Jiggins, F.M., 2014. The evolution and genetics of virus host shifts. PLoS pathogens, 10(11), p.e1004395.

Mabee, P.M., Ashburner, M., Cronk, Q., Gkoutos, G.V., Haendel, M., Segerdell, E., Mungall, C. and Westerfield, M., 2007. Phenotype ontologies: the bridge between genomics and evolution. Trends in ecology \& evolution, 22(7), pp.345-350.

MacNeil, A., Sankalé, J.L., Meloni, S.T., Sarr, A.D., Mboup, S. and Kanki, P., 2007. Long-term intrapatient viral evolution during HIV-2 infection. The Journal of infectious diseases, 195(5), pp.726-733.

Maiden, M.C., 1998. Horizontal genetic exchange, evolution, and spread of antibiotic resistance in bacteria. Clinical Infectious Diseases, 27(Supplement_1), pp.S12-S20.

Mallo, M., 2019. The vertebrate tail: a gene playground for evolution. Cellular and Molecular Life Sciences, pp.1-10.

Martinez, J.L., 2009. The role of natural environments in the evolution of resistance traits in pathogenic bacteria. Proceedings of the Royal Society B: Biological Sciences, 276(1667), pp.2521-2530.

Martínez, J.L., Baquero, F. and Andersson, D.I., 2007. Predicting antibiotic resistance. Nature Reviews Microbiology, 5(12), p.958.

Mazel, D. and Davies, J., 1999. Antibiotic resistance in microbes. Cellular and Molecular Life Sciences CMLS, 56(9-10), pp.742-754.

Miller, M.P. and Kumar, S., 2001. Understanding human disease mutations through the use of interspecific genetic variation. Human molecular genetics, 10(21), pp.2319-2328

Mitteroecker, P., 2019. How human bodies are evolving in modern societies. Nature ecology \& evolution, 3(3), p.324.

Moitra, K. and Dean, M., 2011. Evolution of ABC transporters by gene duplication and their role in human disease. Biological chemistry, 392(1-2), pp.29-37.

Moore, P.L., Gray, E.S., Wibmer, C.K., Bhiman, J.N., Nonyane, M., Sheward, D.J., Hermanus, T., Bajimaya, S., Tumba, N.L., Abrahams, M.R. and Lambson, B.E., 2012. Evolution of an HIV glycan-dependent broadly neutralizing antibody epitope through immune escape. Nature medicine, 18(11), p.1688.

Moya, A., Holmes, E.C. and González-Candelas, F., 2004. The population genetics and evolutionary epidemiology of RNA viruses. Nature Reviews Microbiology, 2(4), p.279.

Nelson, M.I. and Holmes, E.C., 2007. The evolution of epidemic influenza. Nature reviews genetics, 8(3), p.196.

Paillard, C., Le Roux, F. and Borrego, J.J., 2004. Bacterial disease in marine bivalves, a review of recent studies: trends and evolution. Aquatic Living Resources, 17(4), pp.477-498.

Pallen, M.J. and Wren, B.W., 2007. Bacterial pathogenomics. Nature, 449(7164), p.835.

Palumbi, S.R., 2001. Humans as the world's greatest evolutionary force. Science, 293(5536), pp.1786-1790. 
Park, D.J., Dudas, G., Wohl, S., Goba, A., Whitmer, S.L., Andersen, K.G., Sealfon, R.S., Ladner, J.T., Kugelman, J.R., Matranga, C.B. and Winnicki, S.M., 2015. Ebola virus epidemiology, transmission, and evolution during seven months in Sierra Leone. Cell, 161(7), pp.1516-1526.

Park, S., Yang, J.S., Kim, J., Shin, Y.E., Hwang, J., Park, J., Jang, S.K. and Kim, S., 2012. Evolutionary history of human disease genes reveals phenotypic connections and comorbidity among genetic diseases. Scientific reports, 2, p.757.

Penesyan, A., Gillings, M. and Paulsen, I., 2015. Antibiotic discovery: combatting bacterial resistance in cells and in biofilm communities. Molecules, 20(4), pp.5286-5298.

Perron, G.G., Gonzalez, A. and Buckling, A., 2007. Source-sink dynamics shape the evolution of antibiotic resistance and its pleiotropic fitness cost. Proceedings of the Royal Society B: Biological Sciences, 274(1623), pp.2351-2356.

Powers, A.M., Brault, A.C., Shirako, Y., Strauss, E.G., Kang, W., Strauss, J.H. and Weaver, S.C., 2001. Evolutionary relationships and systematics of the alphaviruses. Journal of virology, 75(21), pp.10118-10131.

Prohaska, A., Racimo, F., Schork, A.J., Sikora, M., Stern, A.J., Ilardo, M., Allentoft, M.E., Folkersen, L., Buil, A., Moreno-Mayar, J.V. and Korneliussen, T., 2019. Human disease variation in the light of population genomics. Cell, 177(1), pp.115-131.

Pybus, O.G. and Rambaut, A., 2009. Evolutionary analysis of the dynamics of viral infectious disease. Nature Reviews Genetics, 10(8), p.540.

Rambaut, A., Posada, D., Crandall, K.A. and Holmes, E.C., 2004. The causes and consequences of HIV evolution. Nature Reviews Genetics, 5(1), p.52.

Rasko, D.A. and Sperandio, V., 2010. Anti-virulence strategies to combat bacteria-mediated disease. Nature reviews Drug discovery, 9(2), p.117.

Ryaboshapkina, M. and Hammar, M., 2019. Tissue-specific genes as an underutilized resource in drug discovery. Scientific reports, 9(1), p.7233.

Salmond, G.P. and Welch, M., 2008. Antibiotic resistance: adaptive evolution. The Lancet, 372, pp.S97-S103.

Sharp, P.M. and Hahn, B.H., 2010. The evolution of HIV-1 and the origin of AIDS. Philosophical Transactions of the Royal Society B: Biological Sciences, 365(1552), pp.2487-2494.

Shastry, B.S., 2007. SNPs in disease gene mapping, medicinal drug development and evolution. Journal of human genetics, 52(11), pp.871-880.

Tan, Y.T., Tillett, D.J. and McKay, I.A., 2000. Molecular strategies for overcoming antibiotic resistance in bacteria. Molecular medicine today, 6(8), pp.309-314.

Tishkoff, S.A. and Verrelli, B.C., 2003. Patterns of human genetic diversity: implications for human evolutionary history and disease. Annual review of genomics and human genetics, 4(1), pp.293-340.

Trevathan, W., 2018. Evolutionary medicine. The International Encyclopedia of Biological Anthropology, pp.1-4.

Tursi, A. and Papagrigoriadis, S., 2009. the current and evolving treatment of colonic diverticular disease. Alimentary pharmacology \& therapeutics, 30(6), pp.532-546. 
Wang, L., Valderramos, S.G., Wu, A., Ouyang, S., Li, C., Brasil, P., Bonaldo, M., Coates, T., Nielsen-Saines, K., Jiang, T. and Aliyari, R., 2016. From mosquitos to humans: genetic evolution of Zika virus. Cell host \& microbe, 19(5), pp.561-565.

Wilson, J.W., Schurr, M.J., LeBlanc, C.L., Ramamurthy, R., Buchanan, K.L. and Nickerson, C.A., 2002. Mechanisms of bacterial pathogenicity. Postgraduate medical journal, 78(918), pp.216-224.

Winter, E.E., Goodstadt, L. and Ponting, C.P., 2004. Elevated rates of protein secretion, evolution, and disease among tissue-specific genes. Genome research, 14(1), pp.5461.

Wren, B.W., 2003. The yersiniae-a model genus to study the rapid evolution of bacterial pathogens. Nature Reviews Microbiology, 1(1), p.55.

Zhuang, X., Yang, C., Murphy, K.R. and Cheng, C.H.C., 2019. Molecular mechanism and history of non-sense to sense evolution of antifreeze glycoprotein gene in northern gadids. Proceedings of the National Academy of Sciences, 116(10), pp.4400-4405. 